\title{
Milli-International Unit per Milliliter per Milligram per Kilogram per Day
}

National Cancer Institute

\section{Source}

National Cancer Institute. Milli-International Unit per Milliliter per Milligram per Kilogram per Day. NCI Thesaurus. Code C119399.

A unit of concentration (biologic activity) equal to one milli-international unit per milliliter, divided by milligrams per kilogram per day. 